\title{
Modeled Insulin Sensitivity and Interstitial Insulin Action from a Pilot Study of Dynamic Insulin Sensitivity Tests
}

\author{
Jessica Lin * Ummu Jamaludin ** Paul Docherty ** \\ Normy N. Razak ${ }^{* *}$ Aaron Le Compte** \\ Christopher G. Pretty ${ }^{* *}$ Christopher E. Hann ${ }^{* *}$ \\ Geoffrey M. Shaw ${ }^{* * *}$ J. Geoffrey Chase ${ }^{* *}$ \\ * Department of Medicine, University of Otago Christchurch, New \\ Zealand \\ ** Center for Bioengineering, University of Canterbury, New Zealand \\ *** Department of Intensive Care Medicine, Christchurch Hospital, \\ New Zealand
}

\begin{abstract}
An accurate test for insulin resistance can delay or prevent the development of Type 2 diabetes and its complications. The current gold standard test, CLAMP, is too labor intensive to be used in general practice. A recently developed dynamic insulin sensitivity test, DIST, uses a glucose-insulin-C-peptide model to calculate model-based insulin sensitivity, $S_{I}$. Preliminary results show good correlation to CLAMP. However both CLAMP and DIST ignore saturation in insulin-mediated glucose removal. This study uses the data from 17 patients who underwent multiple DISTs to investigate interstitial insulin action and its influence on modeled insulin sensitivity. The critical parameters influencing interstitial insulin action are saturation in insulin receptor binding, $\alpha_{G}$, and plasma-interstitial diffusion rate, $n_{I}$. Very low values of $\alpha_{G}$ and very low values of $n_{I}$ produced the most intra-patient variability in $S_{I}$. Repeatability in $S_{I}$ is enhanced with modeled insulin receptor saturation. Future parameter study on subjects with varying degree of insulin resistance may provide a better understanding of different contributing factors of insulin resistance.
\end{abstract}

Keywords: insulin sensitivity, insulin resistance, dynamic insulin sensitivity test, intra-patient repeatability, insulin-mediated glucose removal saturation, interstitial insulin

\section{INTRODUCTION}

The prevalence of Type 2 diabetes has reached epidemic proportions and is still on the rise (Wild et al., 2004; Hossain et al., 2007; PriceWaterhouseCoopers, 2001). Type 2 diabetes is usually not diagnosed until complications start to reveal themselves and irreversible damage has happened (ADA, 1998; Gastaldelli et al., 2004; Kleinfield, 2006). However, insulin resistance (IR) has been found to be decreased by $60 \%$ up to 10 years before a diagnosis is made (Martin et al., 1992). If IR can be identified early, the onset of Type 2 diabetes can be significantly delayed or avoided by lifestyle and diet changes (Duncan et al., 2003; McAuley et al., 2002; Nishida et al., 2002; O'Gorman et al., 2006; Tuomilehto et al., 2001). As Type 2 diabetes is a "slow disease", early intervention and prevention would significantly reduce the social and economic costs currently associated with Type 2 diabetes, which mainly consist of chronic treatments (ADA, 2006).

Unfortunately, the "gold standard" test for IR- CLAMP, is too complex and labor intensive to be feasible in a wider clinical setting (DeFronzo et al., 1979). Other shorter clinical tests or surrogate indicators are often too crude to be truly useful (ADA, 1998). A simple test, DIST, providing a model-based insulin sensitivity marker was developed in recent years and correlates well to CLAMP results (Lotz, 2007).

DIST is a dynamic insulin sensitivity test using a low dose of insulin bolus with the addition of a low dose glucose bolus (Lotz, 2007). Measurements are taken for blood glucose, plasma insulin and C-peptide. Insulin sensitivity $S_{I}$, and other patient specific parameters are then calculated from a physiological model of C-peptide-insulin-glucose kinetics and dynamics. In a Monte Carlo study of DIST, it achieves a correlation of $r=0.98$ (90\% CI: 0.97-0.98) in $S_{I}$ to CLAMP ISI (Lotz et al., 2008). The intra-patient variability between $S_{I}$ in different DISTs is reported to be generally between $0-25 \%$.

Due to measurements only available for blood glucose, plasma insulin and C-peptide, model parameters in Lotz (2007) are mostly determined a priori to limit the number of patient specific parameters to be identified. The kinetics of insulin and C-peptide had been extensively studied and well understood (Duckworth et al., 1988; Duckworth and Kitabchi, 1981; Van Cauter et al., 1992). However, what happens in the interstitium and at the receptor level and beyond still presents a lot of unknowns (Duckworth et al., 1998). In particular, dysfunctions at the cellular level are largely speculated to contribute to insulin resistance 
(Duckworth et al., 1998; Barrett et al., 2009; Black et al., 1982; Brownlee, 2001; Bryant et al., 2002).

Saturation in insulin-mediated glucose removal has been observed at varying levels (Natali et al., 2000; Rizza et al., 1981; Prigeon et al., 1996; Nestler et al., 1988; Transberg et al., 1981; Docherty et al., 2010). However, this effect is not taken into account by CLAMP. Therefore, underestimation in insulin sensitivity can happen when performing a hyperinsulinaemic CLAMP, where superphysiological levels of plasma insulin is induced beyond regions of linear relationship between glucose disposal and plasma insulin level (Rizza et al., 1981; Prigeon et al., 1996). The model developed for DIST also ignores insulin effect saturation, though efforts were made to avoid reaching saturation levels during DIST (Lotz, 2007).

This study uses the data from the clinical pilot study of Lotz (2007) to investigate interstitial insulin action and its influence on modeled insulin sensitivity. It attempts to find a modeled interstitial insulin dose-response that best links insulin action in plasma to response in blood glucose levels. The critical parameters influencing the modeled shape of interstitial insulin action are saturation in insulin receptor binding and plasma-interstitial diffusion rate.

\section{GLUCOSE-INSULIN-C-PEPTIDE MODEL}

This study uses the C-peptide model from Lotz et al. (2008) and a glucose-insulin model, ICING, from Lin et al. (2010). The ICING model is an improved model revised from the glucose-insulin models of Lotz et al. (2008) and Chase et al. (2007). The ICING model addresses insulin receptor saturation, which is ignored in Lotz et al. (2008). Therefore this model is used in this study to investigate the level of insulin receptor saturation.

The C-peptide model has a plasma compartment and a interstitial compartment. It is defined:

$$
\begin{aligned}
& \dot{C}=-\left(k_{1}+k_{3}\right) C(t)+k_{2} Y(t)+u_{e n} \\
& \dot{Y}=k_{1} C(t)-k_{2} Y(t)
\end{aligned}
$$

The ICING Model has three compartments for plasma glucose, plasma insulin and interstitial insulin. The model is defined:

$$
\begin{aligned}
\dot{G}= & -p_{G} G(t)-S_{I} G(t) \frac{Q(t)}{1+\alpha_{G} Q(t)} \\
& +\frac{P(t)+E G P_{b}-C N S}{V_{G}} \\
\dot{Q}= & n_{I}(I(t)-Q(t))-n_{C} \frac{Q(t)}{1+\alpha_{G} Q(t)} \\
\dot{I}= & -n_{K} I(t)-\frac{n_{L} I(t)}{1+\alpha_{I} I(t)}-n_{I}(I(t)-Q(t)) \\
& +\frac{u_{e x}(t)}{V_{I}}+\left(1-x_{L}\right) \frac{u_{e n}}{V_{I}}
\end{aligned}
$$

\begin{tabular}{|c|c|c|}
\hline G & Blood glucose level & {$[\mathrm{mmol} / \mathrm{L}]$} \\
\hline$Q$ & nterstitial insulin level & {$[\mathrm{mU} / \mathrm{L}]$} \\
\hline I & Plasma insulin level & {$[\mathrm{mU} / \mathrm{L}]$} \\
\hline$C$ & Plasma C-peptide concentrations & {$[\mathrm{pmol} / \mathrm{L}]$} \\
\hline$Y$ & $\begin{array}{l}\text { Interstitial compartment C-peptide } \\
\text { concentrations }\end{array}$ & {$[\mathrm{pmol} / \mathrm{L}]$} \\
\hline$E G P$ & Endogenous glucose production & $\mathrm{nmol} / \mathrm{mi}$ \\
\hline$E G P_{b}$ & Basal endogenous glucose production & {$[\mathrm{mmol} / \mathrm{mi}$} \\
\hline$C N S$ & $\begin{array}{l}\text { Central nervous system glucose up- } \\
\text { take }\end{array}$ & {$[\mathrm{mmol} / \mathrm{mi}$} \\
\hline$p_{G}$ & $\begin{array}{l}\text { Insulin independent glucose removal } \\
\text { (excluding } C N S \text { ) and the suppression } \\
\text { of } E G P \text { from } E G P_{b} \text { with respect to } G\end{array}$ & {$\left[\min ^{-1}\right]$} \\
\hline$S_{I}$ & $\begin{array}{l}\text { Insulin mediated glucose removal and } \\
\text { the suppression of } E G P \text { from } E G P_{b} \\
\text { with respect to } G \text { and } Q\end{array}$ & {$[\mathrm{~L} / \mathrm{mU} / \mathrm{m}$} \\
\hline$\alpha_{G}$ & $\begin{array}{l}\text { Saturation parameter for insulin me- } \\
\text { diated glucose removal }\end{array}$ & {$[\mathrm{L} / \mathrm{mU}]$} \\
\hline$V_{G}$ & Plasma glucose distribution volume & \\
\hline$P(t)$ & njection & {$[\mathrm{mmol} / \mathrm{mi}$} \\
\hline$n_{I}$ & $\begin{array}{l}\text { Plasma-interstitium insulin diffusion } \\
\text { rate }\end{array}$ & . 1 \\
\hline$n_{C}$ & receptor-bound insulin degradation & {$\left[\min ^{-1}\right]$} \\
\hline$n_{K}$ & insulin clearance through kidneys & {$\left[\min ^{-1}\right]$} \\
\hline$n_{L}$ & insulin clearance through liver & {$\left[\min ^{-1}\right]$} \\
\hline$\alpha_{I}$ & $\begin{array}{l}\text { Saturation parameter for insulin } \\
\text { clearance through liver }\end{array}$ & {$[\mathrm{L} / \mathrm{mU}]$} \\
\hline$u_{e x}(t)$ & Exogenous insulin & {$[\mathrm{mU} / \mathrm{min}$} \\
\hline$u_{e n}(t)$ & Endogenous insulin & {$[\mathrm{mU} / \mathrm{min}$} \\
\hline$V_{I}$ & Insulin distribution & {$[\mathrm{L}]$} \\
\hline$x_{1}$ & tic clearance & \\
\hline,$k 2$ & C-peptide transport rates & [min] \\
\hline
\end{tabular}

Table 1 lists the nomenclature for Equations (1)-(5).

This study focuses on Equations (4), which defines the insulin action in interstitium. Saturation parameter for insulin receptor binding is $\alpha_{G}$. The receptor-bound insulin
Table 1. Nomenclature

is $Q /\left(1+\alpha_{G} Q\right)$, coupled with $S_{I}$ for glucose removal to cells. Insulin degrading enzyme then degrades the receptor bound insulin interstitium at a rate $n_{C}$ (Duckworth et al., 1998). The value of $n_{C}$ is linked to $n_{I}$ by the steady state ratio between $I$ and $Q$ (Lotz, 2007).

\section{METHODS}

\subsection{Study Cohort}

Data from 17 patients were used in this study. These patients were recruited for the pilot study of DIST Lotz (2007). Each patient under went at least two DISTs at different times. Three different doses of insulin DISTs are performed for the pilot study. A low dose test involves an intravenous glucose injection of $5 \mathrm{~g}$ followed by a intravenous insulin injection of $0.5 \mathrm{U}$. A median dose test uses $10 \mathrm{~g}$ of glucose and $1 \mathrm{U}$ insulin. A high dose test uses $20 \mathrm{~g}$ glucose and $2 \mathrm{U}$ insulin. Table 2 summarizes the tests these patients underwent. More details on the patient cohort and the pilot study can be found in Lotz (2007).

Table 2. Participant Details Summary

\begin{tabular}{c|c|c|c|c|c} 
Group & $\begin{array}{c}\text { Number } \\
(\mathrm{M} / \mathrm{F})\end{array}$ & $\begin{array}{c}\text { BMI (SD) } \\
\left(\mathrm{kg} / \mathrm{m}^{2}\right)\end{array}$ & low & medium & high \\
\hline NGT\# & $14(5 / 9)$ & $27.2(6.7)$ & 7 & 22 & 5 \\
T2DM/IFG\# & $4(1 / 3)$ & $31.2(4.1)$ & 4 & 4 & 2 \\
$\#$ NGT $=$ normal glucose tolerance. T2DM = Type 2 diabetes \\
mellitus. IFG = impaired fasting glucose.
\end{tabular}




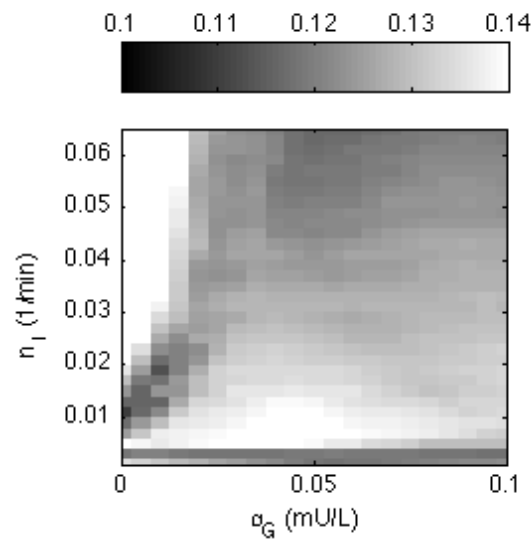

(a) Median variability from all subjects

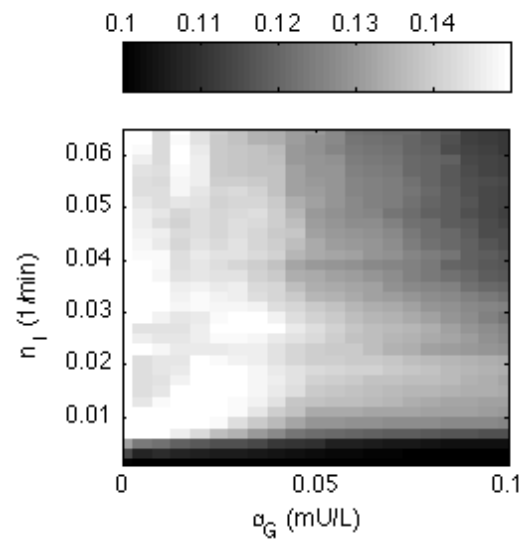

(b) Inter-quartile range of variability amongst subjects

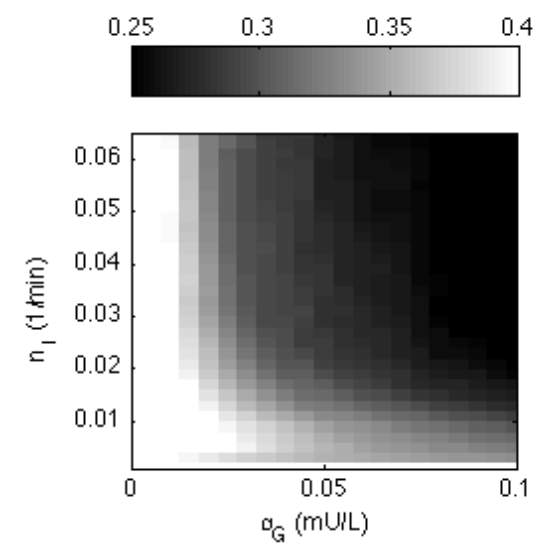

(c) $90 \%$ confidence interval in variability amongst subjects

Fig. 1. Variation of modeled $S_{I}$. Color bars are the level of variations. Darker regions are areas of least intra-patient $S_{I}$ variability from different DIST tests.

\subsection{Patient Specific Parameter Identification}

Measurements in blood glucose, $G(t)$, plasma insulin, $I(t)$ and C-peptide, $C(t)$, were taken during the tests. Patient parameter identification is performed in three stages using these measurements.

In the first stage, endogenous insulin secretion, $u_{e n}$, is calculated using the C-peptide model in Equations (1)(2).

In the second stage, patient specific first pass hepatic clearance, $x_{L}$, and liver insulin clearance, $n_{L}$, are fitted to plasma insulin measurements using insulin and glucose injections, $u_{e x}(t)$ and $P(t)$, and $\mathrm{u}_{e n}(t)$ calculated in the first stage. Equations (4) and (5) are used in this stage, and a good fit will have modeled $I(t)$ in good agreement with plasma insulin measurements. An integral based fitting method (Hann et al., 2005) is used for the identification of $x_{L}$ and $n_{L}$ as a pair.

In the third stage, patient specific insulin sensitivity, $S_{I}$ is solved by fitting Equation (3) to measurements in blood glucose levels. The same integral fitting method is used for the identification.

In the original model of Lotz (2007), $V_{G}$ is also fitted, while $n_{K}, k_{1}, k_{2}$ and $k_{3}$ are calculated to be patient specific using formulas from Van Cauter et al. (1992). Lotz (2007) also used different volumes for plasma and interstitial insulin distribution. However these values do not vary significantly between patients, and are therefore fixed at generic population values for this study.

\subsection{Grid Analysis of $\alpha_{G}$ and $n_{I}$}

Because $\alpha_{G}$ and $n_{I}$ are coupled to compartment $Q$, linking compartments $I$ and $G$, these two parameters cannot be uniquely identified without measurements being available in $Q$. In reality, dynamic response in $Q$ is more or less unmeasurable. This study analyse a grid of $\alpha_{G}$ and $n_{I}$ values to study their influence on $S_{I}$. The analysis range for $n_{I}$ is $[0.001,0.065]$, and for $\alpha_{G}$ is [0 0.1]. These ranges cover the physiological ranges reported in literature, where the boundaries are super- or supra-physiological levels (Nestler et al., 1988; Natali et al., 2000; Prigeon et al., 1996; Transberg et al., 1981; Duckworth and Kitabchi, 1981).

Specifically, the variations in model fitted $S_{I}$ are examined across the grid space. The common metric in evaluating the accuracy of an insulin sensitivity test is its intrapatient repeatability. An insulin sensitivity test producing the least variation in an individual over multiple tests is usually considered to be more accurate. The patient data used for this analysis comprised of 44 DISTs in 17 patients. Each DIST generates a patient specific $S_{I}$ using the method described in Section 3.2. The intra-patient variability in $S_{I}$ is calculated as:

$$
\text { variability }=\frac{\sum a b s\left(S_{I_{1 \ldots n}}-\bar{S}_{I}\right)}{\sum S_{I_{1 \ldots n}}}
$$

where $\mathrm{n}$ is the number of $S_{I}$ from a single patient.

\section{RESULTS}

The fitted $S_{I}$ for each subject in the parameter space of $\alpha_{G}=0 \rightarrow 0.1$ and $n_{I}=0.001 \rightarrow 0.065$ generally decrease with increasing $n_{I}$, and to a lesser degree, decreasing $\alpha_{G}$. The variation in $S_{I}$ in the parameter space across the 17 subjects can be seen in Figure 1

The intra-patient variation in $S_{I}$ is generally low within the parameter space studied, as shown in Figure 1(a). The degree of variation is comparable to the modeled $S_{I}$ from the original pilot study of (Lotz, 2007), which reported variation generally between $0-25 \%$. The darker regions in Figure 1(b) are parameter values producing tighter interquartile spread of $S_{I}$ variability across all subjects. The darker areas are similar to areas of low median variability from all patients in Figure 1(a). Figure 1(c) effectively shows that low $a l p h a_{G}$ and low $n_{I}$ results in more cohort outliers of large intra-patient variability.

The spread of $S_{I}$ variability across 17 patients can be seen in Figure 2. The combination $\left[\alpha_{G}, n_{I}\right]=[0,0.049]$ represents the population values from the original DIST 


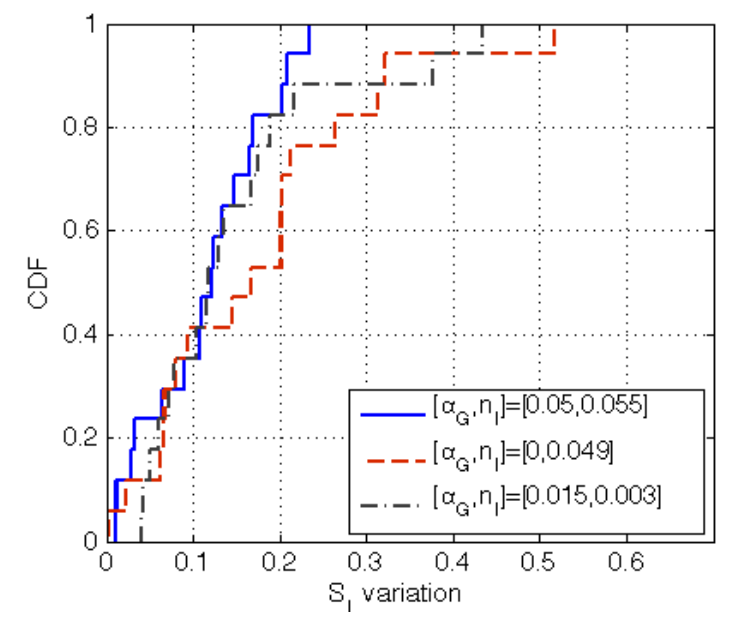

Fig. 2. Cumulative distribution of patient $S_{I}$ variability at different $\alpha_{G}$ and $n_{I}$ values

model Lotz et al. (2008). The modeled $S_{I}$ using $\left[\alpha_{G}, n_{I}\right]=$ $[0,0.049]$ in this study correlates well to the $S_{I}$ calculated using the original DIST model where more parameters are patient specific Lotz et al. (2008). The $r$ value of 0.93 suggests that model accuracy is not compromised by adapting population values in parameters which involved patient specific calculation in the original DIST model. The correlation decreases for the other two combinations of parameter values shown in Figure 2, where $r=0.85$ and 0.7 when $\left[\alpha_{G}, n_{I}\right]=[0.05,0.055]$ and $[0.015,0.003]$.

Although the combination of $\left[\alpha_{G}, n_{I}\right]=[0.015,0.003]$ limited the variability of intra-patient $S_{I}$, the resulting $S_{I}$ is almost equally high for all patients, losing its diagnostic value in insulin resistance screening. The correlation to the original DIST $S_{I}$ dropped significantly to $r=0.70$. The same results are found when extreme values of $\alpha_{G}$ is used. The correlation dropped to $r=0.78$ when $\left[\alpha_{G}\right.$, $\left.n_{I}\right]=[0.1,0.065]$. The decrease in $r$ value is however not as significant as lowing $n_{I}$. The combination $\left[\alpha_{G}\right.$, $\left.n_{I}\right]=[0.05,0.055]$ appears to deliver good intra-patient variability while maintaining good diagnostic accuracy. This set of parameter values produced low median $S_{I}$ variation amongst all subjects where the inter-quartile range is also tight, as seen in Figure 1. The correlation to the original DIST $S_{I}$ is $r=0.85$. The identified $S_{I}$ follows the same trend as the original DIST $S_{I}$ and identified patients with impaired glucose tolerance with similar accuracy.

The combinations of $\alpha_{G}$ and $n_{I}$ producing the lowest intrapatient $S_{I}$ variability for each patient can be seen in Figure 3 . The best combinations from each patient are scatter over the parameter space. This may be an indication that these parameters have significant inter-patient variability.

A typical DIST test response from a patient is shown in Figure 4. The model fits to plasma insulin measurements using different parameter values of $\alpha_{G}$ and $n_{I}$ are effectively equally good across the physiological parameter space. Therefore, patient specific $\alpha_{G}$ and $n_{I}$ cannot be solved simultaneously with $n_{L}$ and $x_{L}$ given that plasma insulin levels are the only measurements available. The effect of $\alpha_{G}$ and $n_{I}$ on the shape of insulin at the receptor

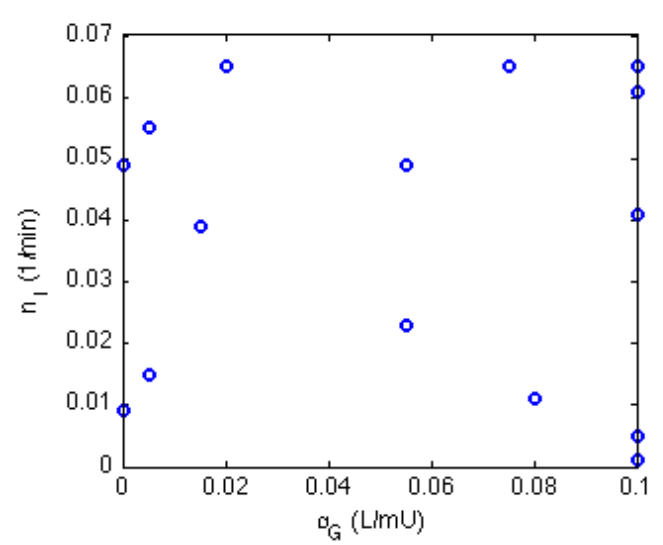

Fig. 3. $\alpha_{G}$ and $n_{I}$ values for the lowest $S_{I}$ variability in each patient

level (i.e. the effective insulin for glucose removal) can be seen in Figure 4. Within the physiological range, larger $\alpha_{G}$ results in a near uniform shift in the level of receptor bound insulin, whereas smaller $n_{I}$ causes the shape of receptor bound insulin to be flatter with a delay in peak time.

\section{DISCUSSION}

This study attempted to investigate the relationship between insulin sensitivity and the shape of time-course receptor bound insulin. With the available plasma insulin and C-peptide data, the kinetics of insulin is well understood in the plasma compartment. However, what happens in the interstitium and at the receptor level and beyond still presents a lot of unknowns. In this study, the critical parameters influencing the shape of receptor bound insulin levels are the plasma-interstitium diffusion rate, $n_{I}$, and receptor binding saturation parameter, $\alpha_{G}$.

The level of saturation in insulin-mediated glucose removal has been reported across a wide range. The plasma insulin level at half maximal action of glucose removal has been reported to be between $50-1000 \mathrm{mU} / \mathrm{L}$. This is effectively equivalent to an $\alpha_{G}$ between 0.04 and near zero (Natali et al., 2000; Rizza et al., 1981; Prigeon et al., 1996; Nestler et al., 1988; Transberg et al., 1981; Docherty et al., 2010). The saturation in insulin-mediated glucose removal may not simply be due to the number of available receptors. A delay in insulin transportation to the skeletal muscle, common in insulin resistant individuals, would also been seen as saturation in insulin-mediated glucose removal (Barrett et al., 2009; Prigeon et al., 1996). In addition, the dynamic response of endogenous glucose production to the insulin injection is not accounted for in this study, due to limited available data. The underestimation of endogenous glucose production will cause glucose removal to appear slower, effectively adding to the saturation effect.

The level of modeled $\alpha_{G}$ has been found to have a magnification effect in insulin sensitivity in data from critically ill patient receiving intensive insulin therapy Chase et al. (2004). It can be seen in Figure 4(b), varying $\alpha_{G}$ shifts the magnitude of the modeled "effective" insulin without influencing the time of peak action. Therefore $\alpha_{G}$ does not impact on $S_{I}$ as much as $n_{I}$. In the 17 patients evaluated in this study, including the saturation 


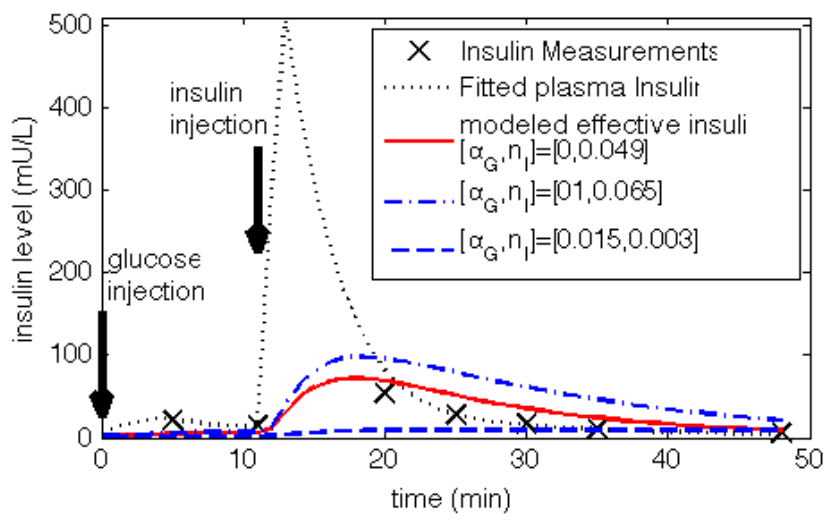

(a) Plasma and effective insulin

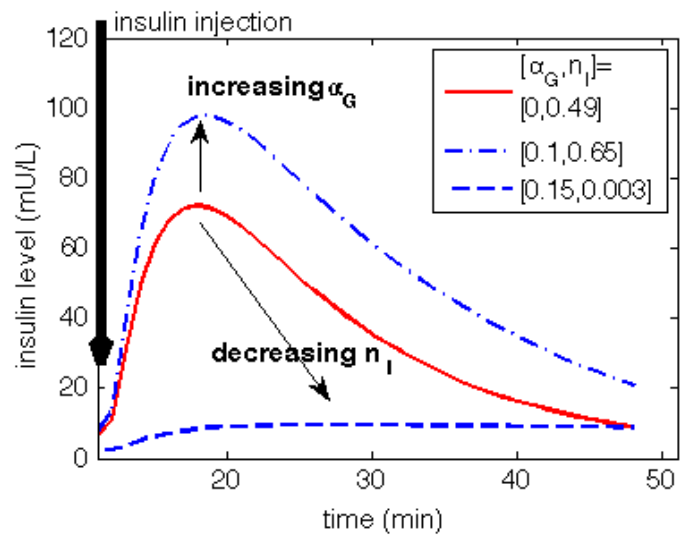

(b) Effective insulin

Fig. 4. Typical DIST test response. Subfigure (b) focuses on the shape of effective (receptor bound) insulin with different $\alpha_{G}$ and $n_{I}$.

parameter $\alpha_{G}$ definitely enhanced the repeatability of the the modeled $S_{I}$ within a patient, as this eliminates the outlying large variability seen in the low $\alpha_{G}$ region in Figure 1(c).

The level of $n_{I}$ has both a magnification effect as well as phasing effect on the shape of effective insulin. When the level of $n_{I}$ decreases, less insulin is able to reach interstitium before being cleared from plasma by the liver and kidneys. The value for $n_{I}$ in the original DIST model was calculated from formulas developed using C-peptide data (Van Cauter et al., 1992). Using these formulas, the values of $n_{I}$ amongst the 17 subjects in this study range between 0.048-0.05. Details for this calculation can be found in Van Cauter et al. (1992) and Lotz (2007). A population $n_{I}$ value of 0.055 is found to provide good intrapatient repeatability in $S_{I}$.

In the validation study of the glucose-insulin model, ICING, using clinical data from critically ill patients receiving intensive insulin therapy, $n_{I}$ was found to be very low at $0.003 \mathrm{~min}^{-1}$ (Lin et al., 2010). This may indicate significantly impaired trans-capillary transport for patients who are critically ill. In particular, sepsis causes a dysfunction in micro-circulation as well as cell metabolism, and is a condition that is prevalent in critical care (Träger and Radermacher, 2003).

Overall, this study presents a method that independently examines $\alpha_{G}$ and $n_{I}$ under the limitation in available data. Cutting down the number of patient specific parameters did not seem to compromise the model accuracy, as very low fitting error in plasma insulin measurements is always achieved. More test data from larger cohorts will enable a more in-depth study of saturation in mediated glucose removal and plasma-interstitium insulin diffusion, or the action of insulin in the interstitum in general. A cohort of patients with mixed levels of insulin resistance will also further validate the accuracy of the modeled $S_{I}$. "Customising" patient $\alpha_{G}$ and $n_{I}$ by finding the parameter values providing the best repeatability in $S_{I}$ may reveal further information in the underlying factors of an individual's insulin resistance.

\section{CONCLUSIONS}

The intra-patient repeatability of $S_{I}$ and its link to interstitial insulin action is studied in 17 patients. Very low values of insulin receptor saturation $\alpha_{G}$ and very low values of plasma-interstitial insulin diffusion $n_{I}$ are found to produce the most intra-patient variability in $S_{I}$. A model accounting for insulin receptor saturation enhanced the repeatability in $S_{I}$. A larger cohort will enable a more in-depth investigation into the relationship between interstitial insulin action and insulin sensitivity. A parameter study on subjects with varying degrees of insulin resistance may provide a better understanding of the contributing factors of insulin resistance.

\section{REFERENCES}

ADA (1998). Consensus development conference on insulin resistance. 5-6 november 1997. American Diabetes Association. Diabetes Care, 21(2), 310-4.

ADA (2006). Diagnosis and classification of diabetes mellitus. Diabetes Care, 29(suppl 1), S43-8.

Barrett, E.J., Eggleston, E.M., Inyard, A.C., Wang, H., Li, G., Chai, W., and Liu, Z. (2009). The vascular actions of insulin control its delivery to muscle and regulate the rate-limiting step in skeletal muscle insulin action. Diabetologia, 52(5), 752-64.

Black, P.R., Brooks, D.C., Bessey, P.Q., Wolfe, R.R., and Wilmore, D.W. (1982). Mechanisms of insulin resistance following injury. Ann Surg, 196(4), 420-35.

Brownlee, M. (2001). Biochemistry and molecular cell biology of diabetic complications. Nature, 414(6865), 813-20. doi:10.1038/414813a.

Bryant, N.J., Govers, R., and James, D.E. (2002). Regulated transport of the glucose transporter glut4. Nat Rev Mol Cell Biol, 3(4), 267-77. doi:10.1038/nrm782.

Chase, J.G., Shaw, G.M., Lin, J., Doran, C.V., Bloomfield, M., Wake, G.C., Broughton, B., Hann, C., and Lotz, T. (2004). Impact of insulin-stimulated glucose removal saturation on dynamic modelling and control of hyperglycaemia. International Journal of Intelligent Systems Technologies and Applications (IJISTA), 1(1/2), 79-94. Chase, J.G., Shaw, G.M., Lotz, T., Le Compte, A.J., Wong, J., Lin, J., Lonergan, T., Willacy, M., and Hann, 
C.E. (2007). Model-based insulin and nutrition administration for tight glycaemic control in critical care. Current drug delivery, 4(4), 283-96.

DeFronzo, R., Tobin, J., and Andres, R. (1979). Glucose clamp technique: a method for quantifying insulin secretion and resistance. Am J Physiol, 237(3), E214-23.

Docherty, P.D., Chase, J.G., Hann, C.E., Lotz, T.F., Lin, J., McAuley, K.A., and Shaw, G.M. (2010). The identification of insulin saturation effects during the dynamic insulin sensitivity test. Open Med. Inform. J., in review.

Duckworth, W., Hamel, F., and Peavy, D. (1988). Hepatic metabolism of insulin. Am J Med, 85(5A), 71-6.

Duckworth, W. and Kitabchi, A. (1981). Insulin metabolism and degradation. Endocr Rev, 2(2), 21033.

Duckworth, W.C., Bennett, R.G., and Hamel, F.G. (1998). Insulin degradation: progress and potential. Endocr Rev, 19(5), 608-24.

Duncan, G., Perri, M., Theriaque, D., Hutson, A., Eckel, R., and Stacpoole, P. (2003). Exercise training, without weight loss, increases insulin sensitivity and postheparin plasma lipase activity in previously sedentary adults. Diabetes Care, 26(3), 557-562.

Gastaldelli, A., Ferrannini, E., Miyazaki, Y., Matsuda, M., and DeFronzo, R. (2004). Beta-cell dysfunction and glucose intolerance: results from the San Antonio metabolism (SAM) study. Diabetologia, 47(1), 31-9.

Hann, C.E., Chase, J.G., Lin, J., Lotz, T., Doran, C.V., and Shaw, G.M. (2005). Integral-based parameter identification for long-term dynamic verification of a glucoseinsulin system model. Computer Methods and Programs in Biomedicine, 77(3), 259-70.

Hossain, P., Kawar, B., and Nahas, M.E. (2007). Obesity and diabetes in the developing world-a growing challenge. The New England Journal of Medicine, 356(3), 213-5. doi:10.1056/NEJMp068177.

Kleinfield, N.R. (2006). Diabetes and its awful toll quietly emerge as a crisis. New York Times, January 9.

Lin, J., Razak, N.N., Pretty, C., Le Compte, A., Docherty, P., Parente, J.D., Shaw, G.M., Hann, C.E., and Chase, J.G. (2010). A physiological intensive control insulinnutrition-glucose (ICING) model validated in critically ill patients. Computer Methods and Programs in Biomedicine, in review.

Lotz, T. (2007). High resolution clinical model-based assessment of insulin sensitivity. PhD Thesis, Mechanical Engineering, University of Canterbury, Christchurch, New Zealand.

Lotz, T.F., Chase, J.G., McAuley, K.A., Shaw, G.M., Wong, X.W., Lin, J., Le Compte, A.J., Hann, C.E., and Mann, J.I. (2008). Monte Carlo analysis of a new modelbased method for insulin sensitivity testing. Computer methods and programs in biomedicine, 89(3), 215-25.

Martin, B.C., Warram, J.H., Krolewski, A.S., Bergman, R.N., Soeldner, J.S., and Kahn, C.R. (1992). Role of glucose and insulin resistance in development of type 2 diabetes mellitus: results of a 25-year follow-up study. Lancet, 340(8825), 925-9.

McAuley, K., Williams, S., Mann, J., Goulding, A., Chisholm, A., Wilson, N., Story, G., McLay, R., Harper, M., and Jones, I. (2002). Intensive lifestyle changes are necessary to improve insulin sensitivity: a randomized controlled trial. Diabetes Care, 25(3), 445-52.

Natali, A., Gastaldelli, A., Camastra, S., Sironi, A., Toschi, E., Masoni, A., Ferrannini, E., and Mari, A. (2000). Dose-response characteristics of insulin action on glucose metabolism: a non-steady-state approach. Am J Physiol Endocrinol Metab, 278(5), E794-801.

Nestler, J., Clore, J., and Blackard, W. (1988). Reduced insulin clearance in normal subjects due to extreme hyperinsulinemia. Am J Med Sci, 295(1), 15-22.

Nishida, Y., Tokuyama, K., Nagasaka, S., Higaki, Y., Fujimi, K., Kiyonaga, A., Shindo, M., Kusaka, I., Nakamura, T., Ishikawa, S., Saito, T., Nakamura, O., Sato, Y., and Tanaka, H. (2002). S(G), S(I), and EGP of exercise-trained middle-aged men estimated by a twocompartment labeled minimal model. Am J Physiol Endocrinol Metab, 283(4), E809-16.

O'Gorman, J.D., Karlsson, H., McQuaid, S., Yousif, O., Rahman, Y., Gasparro, D., Glund, S., Chibalin, A., Zierath, J., and Nolan, J. (2006). Exercise training increases insulin-stimulated glucose disposal and GLUT4 (SLC2A4) protein content in patients with type 2 diabetes. Diabetologia, 49(12), 2983-2992.

PriceWaterhouseCoopers (2001). Type 2 diabetes, managing for better health outcomes. Technical report.

Prigeon, R.L., Røder, M.E., Porte, D., and Kahn, S.E. (1996). The effect of insulin dose on the measurement of insulin sensitivity by the minimal model technique. Evidence for saturable insulin transport in humans. The Journal of clinical investigation, 97(2), 501-7.

Rizza, R., Mandarino, L., and Gerich, J. (1981). Doseresponse characteristics for effects of insulin on production and utilization of glucose in man. Am J Physiol, 240(6), E630-639.

Träger, K. and Radermacher, P. (2003). Catecholamines in the treatment of septic shock: effects beyond perfusion. Crit care and resuscitation: J of Australasian Academy of Crit Care Med, 5(4), 270-6.

Transberg, K., Hagander, P., and Thorell, J. (1981). Disappearance of insulin in man: variation with the plasma insulin level. Acta Endocrinol (Copenh), 97, 391-397.

Tuomilehto, J., Lindström, J., Eriksson, J.G., Valle, T.T., Hämäläinen, H., Ilanne-Parikka, P., KeinänenKiukaanniemi, S., Laakso, M., Louheranta, A., Rastas, M., Salminen, V., Uusitupa, M., and Group, F.D.P.S. (2001). Prevention of type 2 diabetes mellitus by changes in lifestyle among subjects with impaired glucose tolerance. The New Eng J of Med, 344(18), 134350 .

Van Cauter, E., Mestrez, F., Sturis, J., and Polonsky, K. (1992). Estimation of insulin secretion rates from Cpeptide levels. Comparison of individual and standard kinetic parameters for C-peptide clearance. Diabetes, 41(3), 368-77.

Wild, S., Roglic, G., Green, A., Sicree, R., and King, H. (2004). Global prevalence of diabetes: estimates for the year 2000 and projections for 2030. Diabetes Care, 27(5), $1047-53$. 